\title{
Analysis of labor induction in a tertiary care hospital
}

\author{
Meenakshi Tanwar*, Anjali Choudhary, Shweta Mishra
}

Department of Obstetrics and Gynecology, SGRRIHMS, Dehradun, Uttarakhand, India

Received: 10 September 2020

Accepted: 09 October 2020

\section{*Correspondence:}

Dr. Meenakshi Tanwar,

E-mail: meenakshi220879@gmail.com

Copyright: ( ) the author(s), publisher and licensee Medip Academy. This is an open-access article distributed under the terms of the Creative Commons Attribution Non-Commercial License, which permits unrestricted non-commercial use, distribution, and reproduction in any medium, provided the original work is properly cited.

\section{ABSTRACT}

Background: Induction of labour (IOL) is a very common labour room procedure. Although labor is a natural physiological process, deliberate intervention in the form of induction may be required in many instances. It is needed in almost $20 \%$ of pregnant women for a variety of indications. The objective is to evaluate indications, different methods, and feto-maternal outcome of induced labour in tertiary care hospital.

Methods: This was a retrospective study of IOL conducted in the department of obstetrics and gynecology, Shri Guru Ram Rai institute of medical and health sciences, Dehradun, Uttarakhand. Women who underwent IOL beyond 28 weeks gestation with single cephalic presentation with no contraindication for vaginal birth were included in the study. Statistical analysis was done with Microsoft excel.

Results: A total of 1532 women delivered in the hospital during the study period. Among them, 498 women were induced $(32.5 \%)$. Most common method of induction was misoprostol $(40.36 \%)$ followed by prostaglandin E2 gel $(26.90 \%)$. Out of 498 inductions, 377 women delivered vaginally making success of induction around $75.70 \%$. Among them, 335 women had normal delivery (67.26\%) and 42 women required instrumental delivery (8.4\%) and 121 women underwent lower segment caesarean section (LSCS) (24.29\%).

Conclusions: Elective inductions of labor in properly selected indications at optimized timings aid in achieving a favorable maternal and fetal outcome. Methods of inductions, timing and intrapartum monitoring plays an important role in influencing obstetric outcome.

Keywords: Labour inductions, Indications for inductions of labour, Methods of labour inductions, Analysis of labour induction

\section{INTRODUCTION}

Induction of labour (IOL) is defined as artificial initiation of uterine contraction to achieve a vaginal birth-before spontaneous onset of labour. IOL is a very common labour room procedure. ${ }^{1}$ Although labor is a natural physiological process, deliberate intervention in the form of induction may be required in many instances. It is needed in almost $20 \%$ of women for various indications. ${ }^{2,3}$ In developed countries one in every four labors may be an induced labor. In recent years in incidences and indications for IOL are rising so are its associated complications. The incidence of induction has increased in past few decades being about 8-
$33 \%$ in Europe, $23 \%$ in United States and a highest of $35 \%$ in Sri Lanka. ${ }^{4}$

Judicious and timely termination of pregnancy is often an intervention of choice in many high-risk pregnancies in order to accomplish better outcomes for both mother and child. IOL is usually considered when benefits of prompt vaginal delivery outweigh the risks of waiting for spontaneous onset of labor. ${ }^{5,7}$ It is also considered the most appropriate course of action when vaginal route of delivery is considered most apt rather than just the absence of contraindication to vaginal delivery. ${ }^{6-8}$ 
Labor induction may be dictated by a medical or an obstetrical complication of pregnancy or is chosen for nonmedical or social reasons. ${ }^{6}$ Most common indications of labor induction include post-dated pregnancies, premature rupture of membrane, hypertensive disorders, chorioamnionitis, intrauterine growth restriction, intrauterine fetal demise, intrahepatic cholestasis of pregnancy and maternal medical conditions. ${ }^{9}$ Many methods have been used to evoke uterine contraction with an aim to procure vaginal birth and can be mechanical, medical or surgical or combined methods. Mechanical methods include, sweeping and stretching of membranes, use of Foley's catheter or laminaria tent, medical methods use externally administered prostaglandins like misoprostol or PGE2 gel and oxytocin. ${ }^{10}$ Several factors may influence the choice of method for induction of labor including, pre-induction cervical status (Bishop score), membrane status, parity and provider preference. ${ }^{3}$

Despite being a routine labor room procedure, labor induction, it is not without complication and has an intrinsic risk of failure and fetal distress. All inductions of labor irrespective of the method used are fraught with problems and complication and can have adverse effects on feto-maternal outcome. There is a general belief that induction of labor increases the cesarean section rates and may have an impact on maternal experience of labor. There are many issues surrounding IOL that require finetuning and redressal to minimize cesarean section rates and complications. The present study aims to analyze a single center labor induction practices to understand successes and failures of the process.

The objective was to evaluate indications, different methods, and feto-maternal outcome of induced labour in tertiary care hospital Shri Guru Ram Rai Institute of Medical and Health Sciences from August 2019 to January 2020 .

\section{METHODS}

This was a retrospective study of IOL conducted in the department of obstetrics and gynecology, Shri Guru Ram Rai institute of medical and health sciences, Dehradun, Uttarakhand.

\section{Study population}

Women who underwent IOL beyond 28 weeks gestation with single cephalic presentation with no contraindication for vaginal birth were included in the study.

\section{Methods of data collection}

The data comprised of detailed clinical history, associated comorbidities, gestational age, indications of IOL, methods of induction along with maternal and perinatal outcomes were abstracted from hospital delivery register and personal case files. Statistical analysis was done with Microsoft excel.

\section{RESULTS}

A total of 1532 women delivered in the hospital during the study period. Among them, 498 women were induced $(32.5 \%)$. Majority of women belong to age group 26 to 30 years old $(40.36 \%) .43 .17 \%$ women were primigravida, rest were multigravida (56.82\%). Multigravida includes 48 cases of previous caesarean section $(9.6 \%)$ in the study. Maximum number of inductions of labour were done at gestational age of 37-40 weeks as shown in Table 1. Most common indication of induction of labor was post-datism $(26.5 \%)$ followed by term premature rupture of membranes (PROM) (14.05\%), gestational hypertension/preeclampsia (10.4\%), preterm PROM $(8.8 \%)$, intrauterine growth restriction (IUGR) $(8.4 \%)$, antepartum haemorrhage $(5.8 \%)$, IUD (5.6\%), oligohydramnios $(5.6 \%)$, cholestasis of pregnancy $(5.22 \%)$, other (decreased foetal movements, fever, jaundice) $(4.41 \%)$, gestational diabetes mellitus $(2.4 \%)$, eclampsia $(2.2 \%)$ and $\mathrm{Rh}$ incompatible pregnancy $(0.8 \%)$ (Table 2).

Table 1: Demography.

\begin{tabular}{|lll|}
\hline Demographics & Number & $\%$ \\
\hline Age (years) & \multicolumn{2}{l|}{} \\
\hline$<20$ & 7 & 1.4 \\
\hline $20-25$ & 178 & 35.74 \\
\hline $26-30$ & 201 & 40.36 \\
\hline $31-35$ & 76 & 15.26 \\
\hline $36-40$ & 34 & 6.82 \\
\hline$>40$ & 2 & 0.4 \\
\hline Parity & & \\
\hline Primi & 215 & 43.17 \\
\hline Multi & 283 & 56.82 \\
\hline G/A* at time of induction (weeks) & (in weeks) \\
\hline$<34$ & 26 & 5.22 \\
\hline $34-36.6$ & 32 & 6.42 \\
\hline $37-40$ & 308 & 61.84 \\
\hline$>40$ & 132 & 26.50 \\
\hline
\end{tabular}

${ }^{*} \mathrm{G} / \mathrm{A}$ : gestational age, GDM: gestational diabetes melitus, IHCP: intrahepatic cholestasis, IUFD: intrauterine foetal death, PROM: premature rupture of membranes, IUGR: intrauterine growth retardation

Most common method of induction was misoprostol (40.36\%) followed by prostaglandin E2 gel (26.90\%). Among combined methods, preferred method was intracervical Foleys with oxytocin $(10.44 \%)$ followed by intracervical Foleys with misoprostol $(9.28 \%)$ and intracervical Foleys with prostaglandin E2 gel (7.4\%). 28 women received mifepristone followed by misoprostol in cases of confirmed IUD (5.6\%) as shown in Table 3.

\section{Maternal outcome}

Out of 498 induced women, 170 women had prolonged labor $(34.13 \%)$ and 134 had fever $(26.9 \%)$. Postpartum haemorrhage (PPH) occurred in 81 women $(16.26 \%)$, 
which was managed medically, 2 women required blood transfusion. Genital trauma was noted and surgically managed in 14 women $(2.8 \%)$. 6 women had wound infection $(1.20 \%)$ as shown in Table 5. There was no maternal mortality in the present study.

Table 2: Indications of induction.

\begin{tabular}{|lll|}
\hline Indication of induction & Number & $\%$ \\
\hline Post-dated pregnancy & 132 & 26.5 \\
\hline Term PROM & 70 & 14.05 \\
\hline Hypertensive disorders & 50 & 10.04 \\
\hline Pre term PROM & 44 & 8.8 \\
\hline IUGR & 42 & 8.4 \\
\hline Antepartum haemorrhage & 29 & 5.8 \\
\hline IUFD & 28 & 5.6 \\
\hline Oligohydramnios & 28 & 5.6 \\
\hline IHCP & 26 & 5.22 \\
\hline $\begin{array}{l}\text { Others (decreased foetal } \\
\text { movements, fever, jaundice) }\end{array}$ & 22 & 4.41 \\
\hline GDM & 12 & 2.4 \\
\hline Eclampsia & 11 & 2.2 \\
\hline RH incompatibility & 4 & 0.8 \\
\hline
\end{tabular}

\section{Neonatal outcome}

Out of 498 inductions, 469 women had live births (94.1\%). Among 29 still-births, 28 women were pre-diagnosed with intrauterine fetal death (IUFD) for induction and 1 woman had an intrapartum fetal death. One in the women who came with eclampsia at 29 weeks gestation with severe IUGR, labor was induced after explaining about fetal prognosis. Out of 469 live births 67 newborns (14.28\%) required neonatal intensive care (NICU) admission out of which 30 babies $(44.7 \%)$ were premature babies, 14 (20.8\%) babies were admitted for meconium aspiration, 8 $(11 \%)$ had respiratory morbidity and $4(5.9 \%)$ babies had birth asphyxia. 11 neonates $(16.4 \%)$ developed hyperbilirubinemia.

Table 3: Methods of induction.

\begin{tabular}{|lll|}
\hline Method & No. & Percentage \\
\hline Misoprostol & 201 & 40.36 \\
\hline PG E2 GEL & 134 & 26.90 \\
\hline $\begin{array}{l}\text { Intra-cervical Foleys followed } \\
\text { by oxytocin }\end{array}$ & 52 & 10.44 \\
\hline $\begin{array}{l}\text { Intracervical Foleys followed } \\
\text { by misoprostol }\end{array}$ & 46 & 9.28 \\
\hline $\begin{array}{l}\text { Intracervical Foleys followed } \\
\text { by PG E2 gel }\end{array}$ & 37 & 7.4 \\
\hline $\begin{array}{l}\text { Mifepristone followed by } \\
\text { misoprostol }\end{array}$ & 28 & 5.6 \\
\hline
\end{tabular}

Out of 498 inductions, 377 women delivered vaginally making success of induction around $75.70 \%$. Among them, 335 women had normal delivery (67.26\%) and 42 women required instrumental delivery (8.4\%). 121 women underwent lower segment caesarean section (LSCS) $(24.29 \%)$ due to various indications. Highest caesarean rates were noted in women induced with intracervical Foleys with PG E2 gel (29.72\%) and lowest in women induced with intracervical Foleys with misoprostol $(21.72 \%)$ as shown in Table 4. All 28 women who had intrauterine death delivered vaginally.

Table 4: Mode of delivery.

\begin{tabular}{|llll|}
\hline Method of induction & ND no $(\%)$ & Instrumental delivery no. $(\%)$ & LSCS no $(\%)$ \\
\hline Misoprostol $(\mathbf{m}=\mathbf{2 0 1})$ & $131(65.17)$ & $16(7.9)$ & $54(26.86)$ \\
\hline PGE2 gel $(\mathbf{n = 1 3 4 )}$ & $89(66.41)$ & $11(8.2)$ & $34(25.37)$ \\
\hline ICF+oxytocin $(\mathbf{n = 5 2 )}$ & $34(65.38)$ & $6(11.53)$ & $12(23.07)$ \\
\hline ICF+misoprostol $(\mathbf{n = 4 6 )}$ & $32(69.56)$ & $4(8.69)$ & $10(21.7)$ \\
\hline ICF+PG E2 gel $(\mathbf{n = 3 7 )}$ & $22(59.45)$ & $4(10.81)$ & $11(29.72)$ \\
\hline Mifepristone+misoprostol* $(\mathbf{n = 2 8})$ & $27(96.42)$ & $1(3.57)$ & $0(0)$ \\
\hline Total induction $(\mathbf{n = 4 9 8 )}$ & $335(67.26)$ & $42(8.4)$ & $121(24.29)$ \\
\hline
\end{tabular}

ICF-Intracevical Foleys, $\mathrm{PGE}_{2}$ gel-prostaglandin $\mathrm{E}_{2}$ gel, *mifepristone and misoprostol combination were used for induction of labor for intra-uterine fetal death

Table 5: Maternal morbidity.

\begin{tabular}{|l|l|}
\hline Parameter & Number $(\%)$ \\
\hline Prolonged labour & $170(34.13)$ \\
\hline Fever & $134(26.9)$ \\
\hline PPH & $81(16.26)$ \\
\hline Genital trauma & $14(2.8)$ \\
\hline Wound infection & $6(1.20)$ \\
\hline
\end{tabular}




\section{DISCUSSION}

Women who are chosen for elective induction of labor have a potential for successful vaginal birth. Judiciously chosen time, indication and method for induction can influence the outcome. As a medical decision taken for almost $25 \%$ of pregnant women induction of labor merits a justifiable scrutiny. The present study was undertaken to understand different indications, methods and results of induced labors. Majority of women were in the age group 26 to 30 years old $(40.36 \%)$, out of which $43.17 \%$ were primigravidae and $56.82 \%$ women were multigravidas. Maximum number of women were induced at 37-40 weeks of gestation $(61.8 \%)$ followed by $(26.5 \%)$ at $40-42$ weeks, $6.42 \%$ of women were between $34-36$ weeks and $5.22 \%$ of women were less than 34 weeks. Jalil et al quote and induction rate of $8 \%$ out of which the highest number of inductions were done for hypertensive disorders (42\%), followed by post-dated pregnancies (22\%), and premature rupture of membranes $(21 \%) .{ }^{11}$ In our study the most common indication for induction was post-dated pregnancies $(26.5 \%)$, hypertensive disorders (14\%) and PROM (10\%). Our institute has a policy of or induction around 41 weeks of gestation for postdated pregnancy according to the American college of obstetricians and gynecologists (ACOG) guidelines and 26\% women induced for post-datism. Out of 1532 women delivered in the study period $32.5 \%$ were induced labors, out of which $67.26 \%$ women had normal birth, $8.4 \%$ women required instrumental delivery and $24.29 \%$ needed cesarean sections. Rates of induction may vary among hospitals and may be due to practice of following different guidelines, personal preferences and hospital policies.

In a systematic analysis of indications of labor inductions, Kotes et al attribute these practice variations to variability in clinical guidelines. ${ }^{12}$ Many guidelines vary in timing and indications. They analyzed 49 clinical guidelines of varying strength, many of which agree on indications such as, prolonged pregnancy (induce between 41-42 weeks) premature rupture of membranes and term hypertensive disorders (induction, at $\geq 37$ weeks), but there was little consensus about inductions for gestational diabetes, fetal macrosomia, and high maternal body mass index. Mozurkewich et al in their best evidence review for indications of labor inductions analyzed 34 full text articles and assigned 'levels of evidence' based on a GRADE system - that grades the overall quality of evidence as high, moderate-low, and very low and found that the recommendations for labor indications for postterm pregnancies, IUGR, preeclampsia, premature rupture of membranes near term were supported by high quality evidence. ${ }^{13}$ However the evidence was not sufficient to support induction of labor for women with diabetes, twin pregnancy, fetal macrosomia, oligohydramnios, maternal heart disease, and cholestasis of pregnancy. They categorized grading of evidence based upon 'net benefit' of labor induction, whether it does more good or harm and guideline in which labor induction was beneficial was considered good quality recommendation. ${ }^{13}$ They also found that induction for IUGR before term reduces intrauterine fetal death, but increases caesarean deliveries and neonatal deaths. In our study $8.4 \%$ women were induced for IUGR where $47.6 \%$ required cesarean section which was highest in any other category.

Induction of labor is presumed to increase the rate of cesarean deliveries. In our observation $75.71 \%$ women with induced labor had vaginal birth and $24.29 \%$ women required cesarean section out of which majority were done for post-dated pregnancy, IUGR and women with preeclampsia/eclampsia. ACOG recommends labor inductions before 41 weeks should not be done unless for fetal or maternal indications. ${ }^{14}$ Following same principles, we found better success rates with our labor inductions. Pre-induction cervical ripening is also known to reduce cesarean rates. ${ }^{15-17}$ In our study also we found that the success of vaginal delivery was more in labors induced with prior use of ripening agents. Souter and colleagues in a large multicentric randomized controlled trial (RCT) found that elective induction at 39 weeks was associated with reduced cesarean deliveries on the other hand, ACOG recommends inductions for prolonged pregnancy at 41 completed weeks to reduce cesarean rates. ${ }^{15,16}$ In 2014 ACOG came out with document on 'safe prevention of primary cesarean section' in which they provide guidelines for safer labor inductions to reduce sections rates and advocate many changes in the current IOL practices. ${ }^{17}$ In the above study most, inductions were carried out in compliance with the guidelines.

Although justified in many instances labor inductions are not without maternal and fetal consequences. The intentions for labor inductions are always good, taken in the interest of both and fetus and the mother still some complications may arise. In the present study of 498 induced labors, there was only one fresh stillbirth due to intra-partum asphyxia (this was an extremely premature baby of an eclamptic mother) and $13 \%$ of babies required NICU admissions out of which majority were for prematurity and meconium aspiration. $16.4 \%$ babies needed admission to NICU for hyperbilirubinemia. Abisowo et al in their study of feto-maternal outcomes in induced versus spontaneous labors they observed five perinatal death in 227 induced labors and three perinatal deaths in women with spontaneous labors. ${ }^{16}$ Darney, and colleagues while comparing induced labor at term versus expectant management, found a cesarean rate of $16 \%$ with $0.2 \%$ perinatal mortality and NICU admission of $6.2 \% .^{18}$ During their study they did not find increased odds of operative vaginal delivery, severe lacerations or shoulder dystocia in induced labors. In the present study the rate of operative vaginal delivery was $8.4 \%$, perineal trauma $(2.5 \%)$ and wound infection rate of $1.2 \%$ which was comparable to overall incidence and not increased by inductions of labor. There was slight increase in the occurrence of postpartum hemorrhage, at $16.26 \%$ and prolonged labor in $34.1 \%$ which was in agreement of the belief that induced labor are usually associated with 
prolonged labor and PPH when compared to spontaneous labors. There was no maternal mortality in our study.

IOL, though sometimes crucial for management, is not risk free and many women find it uncomfortable. Improving maternal care around child birth in order to improve care for women is a necessary step towards the achievement of the health targets of the sustainable development goals (SDGs). ${ }^{19}$ Labor induction is one such practice toward achieving favorable feto-maternal outcomes in high risk pregnancies. Practiced judiciously for valid indications with carefully chosen time and method, of induction of labor yields fruitful results.

\section{CONCLUSION}

Elective inductions of labor in properly selected indications at optimized timings aid in achieving a favorable maternal and fetal results. Methods of inductions, timing and intrapartum monitoring plays an important role in influencing obstetric outcome.

\section{Funding: No funding sources}

Conflict of interest: None declared

Ethical approval: Not required

\section{REFERENCES}

1. ACOG Committee on Practice Bulletins - Obstetrics ACOG Practice Bulletin No. 107: Induction of labor. Obstet Gynecol. 2009;114:386-97.

2. Weeks AD, Navaratnam K, Alfirevic Z. Simplifying oral misoprostol protocols for the induction of labour. BJOG. 2017;124:1642-5.

3. Caughey AB, Sundaram V, Kaimal AJ, Cheng YW, Gienger A, Little SE, et al. Maternal and neonatal outcomes of elective induction of labor. Evid Rep Technol Assess (Full Rep). 2009;176:1-257.

4. WHO: Global Survey on Maternal and Perinatal Health. Geneva, World Health Organization. 2010.

5. Mozurkewich EL, Chilimigras JL, Berman DR, Perni UC, Romero VC, King VJ, et al. Methods of induction of labour: a systematic review. BMC Pregnancy Childbirth. 2011;11:84.

6. Marconi AM. Recent advances in the induction of labor. F1000Res. 2019;8:1829.

7. National Institute for Health and Clinical Excellence (NICE): Induction of labor. Clinical Guideline 70. 2008.
8. Queensland Clinical Guidelines. Induction of labor. 2017.

9. WHO recommendations for induction of labour. 2011. Available at: http://whqlibdoc.who.int/hq/2011/ WHO_RHR_11.10_eng.pdf. Accessed on: 30 July 2020.

10. Kent A. Induction of Labor. Rev Obstet Gynecol. 2012;5(2):113-4.

11. Jalil G, Malik RM, Suhail N, Razzaque A. Induction of labor, an Audit of Indications and obstetric outcomes in a tertiary care Hospital. Annals. 2004;10(2).

12. Coates D, Homer C, Wilson A, Deady L, Mason E, Foureur M, Henry A. Induction of labour indications and timing: A systematic analysis of clinical guidelines. Women Birth. 2020;33(3):219-30.

13. Mozurkewich E, Chilimigras J, Koepke E, Keeton K, King V. Indications for induction of labour: a bestevidence review. BJOG. 2009;116:626-36.

14. Lothian JA. Safe Prevention of the Primary Cesarean Delivery: ACOG and SMFM Change the Game. J Perinat Educ. 2014;23(3):115-8.

15. Souter V, Painter I, Sitcov K, Caughey AB. Maternal and newborn outcomes with elective induction of labor at term. Am J Obstet Gynecol. 2019;220(3):273.

16. Abisowo OY, Oyinyechi AJ, Olusegun FA, Oyedokun OY, Motunrayo AF, Abimbola OT. Fetomaternal outcome of induced versus spontaneous labour in a Nigerian Tertiary Maternity Unit. Trop J Obstet Gynaecol. 2017;34:21-7.

17. ACOG/SMFM obstetric care consensus. Safe prevention of the primary cesarean delivery. Obstet Gynecol. 2014;123:693-711.

18. Darney BG, Snowden JM, Cheng YW, Jacob L, Nicholson JM, Kaimal A, et al. Elective induction of labor at term compared with expectant management: Maternal and neonatal outcomes. Obstet Gynecol. 2013;122(4):761-9.

19. WHO recommendations: induction of labour at or beyond term. Geneva: World Health Organization. 2018.

Cite this article as: Tanwar M, Choudhary A, Mishra S. Analysis of labor induction in a tertiary care hospital. Int J Reprod Contracept Obstet Gynecol 2020;9:4627-31. 